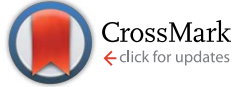

Cite this: J. Mater. Chem. A, 2016, 4 , 19189

Received 23rd September 2016 Accepted 14th November 2016 DOI: $10.1039 / c 6 t a 08268 \mathrm{~h}$

www.rsc.org/MaterialsA

\title{
Insights into the working mechanism of cathode interlayers in polymer solar cells via $\left[\left(\mathrm{C}_{8} \mathrm{H}_{17}\right)_{4} \mathrm{~N}\right]_{4}\left[\mathrm{SiW}_{12} \mathrm{O}_{40}\right] \dagger$
}

\begin{abstract}
Youchun Chen, ${ }^{a}$ Shan Wang, ${ }^{a}$ Lingwei Xue, ${ }^{b}$ Zhiguo Zhang, ${ }^{b}$ Haolong Li, ${ }^{* a}$ Lixin $\mathrm{Wu}{ }^{a}$ Yue Wang, ${ }^{a}$ Fenghong $\mathrm{Li}^{\text {, }}{ }^{\text {a }}$ Fengling Zhang ${ }^{\mathrm{c}}$ and Yongfang $\mathrm{Li}^{\mathrm{b}}$

A low-cost ( $<$ \$1 per g), high-yield ( $>90 \%)$, alcohol soluble surfactant-encapsulated polyoxometalate complex $\left[\left(\mathrm{C}_{8} \mathrm{H}_{17}\right)_{4} \mathrm{~N}\right]_{4}\left[\mathrm{SiW}_{12} \mathrm{O}_{40}\right]$ has been synthesized and utilized as a cathode interlayer (CIL) in polymer solar cells (PSCs). A power conversion efficiency of $10.1 \%$ can be obtained for PSCs based on PTB7-Th (poly[[2,6'-4,8-di(5-ethylhexylthienyl)benzo[1,2-b;3,3-b]-dithiophene][3-fluoro-2[(2-ethylhexyl) carbonyl] thieno [3,4-b]-thiophenediyl]]):PC $\mathrm{C}_{71} \mathrm{BM}([6,6]$-phenyl C71-butyric acidmethyl ester) due to the incorporation of $\left[\left(\mathrm{C}_{8} \mathrm{H}_{17}\right)_{4} \mathrm{~N}\right]_{4}\left[\mathrm{SiW}_{12} \mathrm{O}_{40}\right]$. Combined measurements of current density-voltage characteristics, transient photocurrent, charge carrier mobility and capacitance-voltage characteristics demonstrate that $\left[\left(\mathrm{C}_{8} \mathrm{H}_{17}\right)_{4} \mathrm{~N}_{4}\left[\mathrm{SiW}_{12} \mathrm{O}_{40}\right]\right.$ can effectively increase the built-in potential, charge carrier density and mobility and accelerate the charge carrier extraction in PSCs. Most importantly, the mechanism of using $\left[\left(\mathrm{C}_{8} \mathrm{H}_{17}\right)_{4} \mathrm{~N}_{4}\left[\mathrm{SiW}_{12} \mathrm{O}_{40}\right]\right.$ as the $\mathrm{CIL}$ is further brought to light by $\mathrm{X}$-ray photoemission spectroscopy (XPS) and ultraviolet photoemission spectroscopy (UPS) of the metal/ $\left[\left(\mathrm{C}_{8} \mathrm{H}_{17}\right)_{4} \mathrm{~N}\right]_{4}\left[\mathrm{SiW}_{12} \mathrm{O}_{40}\right]$ interface. The findings suggest that $\left[\left(\mathrm{C}_{8} \mathrm{H}_{17}\right)_{4} \mathrm{~N}\right]_{4}\left[\mathrm{SiW}_{12} \mathrm{O}_{40}\right]$ not only decreased the work function of the metal cathodes but also was $\mathrm{n}$-doped upon contact with the metals, which provide insights into the working mechanism of the CILs simultaneously improving the open circuit voltage, short circuit current and fill factor in the PSCs.
\end{abstract}

\section{Introduction}

Polymer solar cells (PSCs) have drawn great attention owing to their unique advantages of synthetic variability, light weight, low cost, large-area roll to roll fabrication and the lucrative possibility of directly integrating into flexible devices. The power conversion efficiency (PCE) of the PSCs has been over $10 \%$ for single cell devices. ${ }^{1-5}$ One of the efficient strategies to achieve such a high efficiency was the application of an alcohol/ water soluble cathode interlayer (CIL).$^{6-28}$ Alcohol/water-soluble CILs reported so far mainly consist of conjugated polymers ${ }^{6-14}$ and small molecules. ${ }^{15-26}$ However it is difficult to massively utilize the materials for low cost and large-area roll to roll production of PSCs because the CIL molecules containing complicated $\pi$ conjugated units require difficult and complicated synthetic procedures resulting in high cost in terms of

${ }^{a}$ Key Laboratory of Supramolecular Structure and Materials, Jilin University, Changchun 130012,P.R. China.E-mail:fhli@jlu.edu.cn; hl_li@jlu.edu.cn

${ }^{b}$ Beijing National Laboratory for Molecular Sciences, CAS Key Laboratory of Organic Solids, Institute of Chemistry, Chinese Academy of Sciences, P. R. China

${ }^{c}$ Department of Physics, Chemistry and Biology (IFM), Linköping University, Linkoping 58183, Sweden

$\dagger$ Electronic supplementary information (ESI) available. See DOI: $10.1039 / \mathrm{c} 6 \mathrm{ta} 08268 \mathrm{~h}$ production and environment. More importantly the thickness of most conjugated CILs is limited to $\leq 10 \mathrm{~nm}$ due to their inherently insulating nature or low conductivities. This limitation is a big challenge to reproducibly process such ultrathin CILs with good uniformity over large areas without forming pinholes. Even though doping of the materials can increase their conductivities and thicknesses in PSCs, ${ }^{10,27}$ the absorption of thicker CIL films in the visible region is usually not negligible, which diminishes the photocurrent. Therefore there is an urgent need to develop and design environmentally friendly, low cost, and transparent CIL materials which have sufficient conductivity for electrons for large-area roll to roll production of PSCs. Recently a non-conjugated small molecule electrolyte $4,4^{\prime}$ (((methyl(4-sulphonatobutyl)ammonio)bis(propane-3,1-diyl))bis(dimethyl-ammoniumdiyl))bis-(butane-1-sulphonate) as the CIL successfully improved the PCE of the PSCs based on PTB7:PC ${ }_{71} \mathrm{BM}$ (Fig. 1a) up to $10 \%$ though its working mechanism is unclear. ${ }^{28}$ Thereby non-conjugated molecules should be regarded as the potentially promising CIL in PSCs.

Generally CIL molecules contain ammonium salt groups or $N, N$-dimethylamino groups which ensure a better solubility of organic materials in water or alcohol and interfacial dipoles at the interface between the CIL and cathode. Surfactant tetraoctylammonium bromide (TOAB) is one of the common quaternary ammonium salts. Incorporating TOAB as a CIL has resulted 


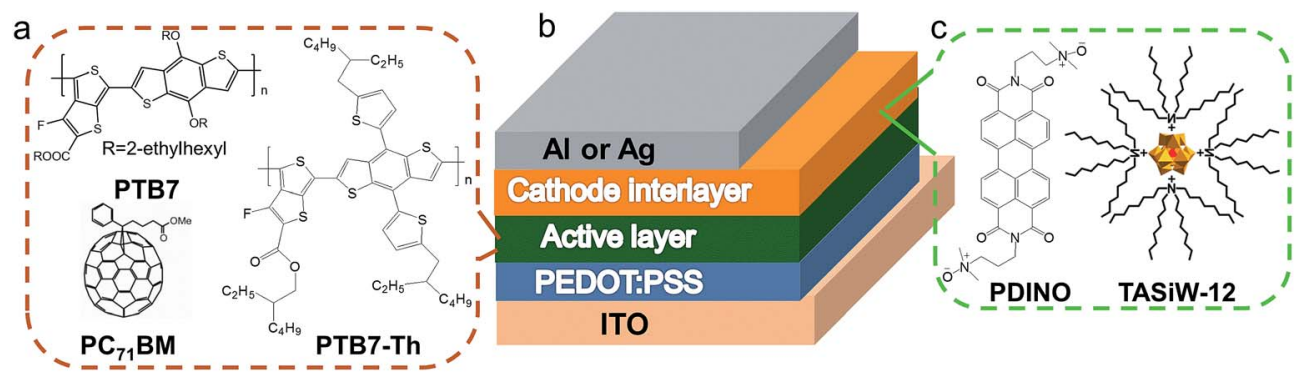

Fig. 1 (a) Molecular structures of PTB7, PTB7-Th and PC 71 BM. (b) Conventional device configuration. (c) Molecular structures of PDINO and TASiW-12.

in a simultaneous increase of short circuit current $\left(J_{\mathrm{sC}}\right)$, open circuit voltage $\left(V_{\mathrm{OC}}\right)$ and fill factor $(\mathrm{FF})$ in the PSCs based on P3HT: $\mathrm{PC}_{61} \mathrm{BM}$ due to the ordered arrangement between $\mathrm{N}^{+}$and $\mathrm{Br}^{-}$in the self-assembled TOAB atop the active layer. ${ }^{29}$ However the nonconductive TOAB formed large island clusters on the active layer. Moreover, polyoxometalates (POMs) as a large family of environmentally friendly inorganic clusters are also expected as the CILs because they show highly tunable structural properties, outstanding electron accepting and favorable electron transporting properties, high transparency in the visible range and facile processing from water or alcohol solutions. ${ }^{30-35}$ Recently $\mathrm{H}_{3} \mathrm{PW}_{12} \mathrm{O}_{40}$ as a CIL gave rise to a simultaneous increase of $J_{\mathrm{SC}}, V_{\mathrm{OC}}$ and FF of the P3HT:PC ${ }_{61} \mathrm{BM}$ based PSCs. ${ }^{36}$ More recent application of some Keggin and Dawson POMs as the CIL was systemically investigated and an enhancement of device performance has been achieved by incorporating an $\sim 2-3 \mathrm{~nm}$ POM interlayer in the PSCs. ${ }^{37}$ However the acidic nature and severe aggregation of the POMs on the active layer are big challenges to the device performance and stability. Therefore neither TOAB nor POMs are suitable for large-area production of PSCs with high efficiency and long lifetime even though both of them are environmentally friendly, low cost and transparent CIL materials resulting in an increase in efficiency of PSCs of small size. In order to overcome their drawbacks and utilize their advantages, we intendedly synthesized a novel alcohol-soluble CIL material $\left[\left(\mathrm{C}_{8} \mathrm{H}_{17}\right)_{4} \mathrm{~N}\right]_{4}\left[\mathrm{SiW}_{12} \mathrm{O}_{40}\right]$ (Fig. 1c, abbreviated TASiW-12) using commercially available cheap TOAB (surfactant) and $\mathrm{H}_{4} \mathrm{SiW}_{12} \mathrm{O}_{40}$ (POM). The advantages of TASiW-12 over other organic CIL materials for large-area roll to roll production of PSCs are evident because of its simple, green (solvents: alcohol and water) and high-yield $(>90 \%)$ synthetic procedures and low cost $(<\$ 1$ per g). Compared to $\mathrm{ZnO}^{38-40}$ it does not need thermal annealing and has better compatibility and adhesion with the active layer due to the introduction of sixteen flexible alkyl chains.

In addition, it should be noted that a definite working mechanism of the CIL in PSCs has scarcely been investigated until now. It is widely believed that the CIL create a negative interfacial dipole (its negative pole pointing toward the metal cathode and its positive pole toward the CIL) between the CIL and cathode, leading to a decrease of work function (WF) of the cathode. However there still are a number of open questions, for example: "Why do the CIL molecules create such a negative interfacial dipole?", "How do the CIL molecules arrange between the metal cathode and the organic active layer?", and "What happens when the CIL molecules come into contact with the metal and the active layer?" It is acceptable that a WF decrease of the cathode due to the interfacial dipole gives rise to an increase of $V_{\mathrm{OC}}$. However interfacial dipole formation at the cathode interlayer cannot explain the increase of $J_{\mathrm{SC}}$ and $\mathrm{FF}$. Therefore detailed studies about the cathode interface are required to reveal the working mechanism of the CIL simultaneously improving $V_{\mathrm{OC}}, J_{\mathrm{SC}}$ and FF in PSCs.

In this contribution, we aim to not only develop a novel CIL TASiW-12 for high-performance PSCs but also elucidate the working mechanism of the CIL simultaneously improving $V_{\mathrm{OC}}$, $J_{\text {SC }}$ and FF using TASiW-12 as a model. When an $\sim 10-15 \mathrm{~nm}$ TASiW-12 film was applied as the CIL in the conventional PSCs based on PTB7-Th:PC ${ }_{71}$ BM (Fig. 1a), PCEs of $10.1 \%$ and $9.8 \%$ were achieved for the devices with $\mathrm{Al}$ or $\mathrm{Ag}$ as a cathode, respectively (Fig. 1b). More importantly combined X-ray photoemission spectroscopic (XPS) and ultraviolet photoemission spectroscopic (UPS) measurements demonstrated the chemical and electronic structures of TASiW-12/Al contact and TASiW-12/Ag contact and accordingly provide the insights into the working mechanism of CILs in the PSCs.

\section{Experimental}

\subsection{Fabrication of polymer solar cells and charge carrier-only devices}

PTB7 (Fig. 1a) and PTB7-Th were purchased from 1-material Inc. $\mathrm{PC}_{71} \mathrm{BM}$ was purchased from American Dye Source. All materials were used as received. The structure of the devices is ITO/ PEDOT:PSS/active layer/CIL/Al. Firstly PEDOT:PSS (Baytron PVP Al 4083) was spin-coated onto a cleaned ITO and annealed in air at $110^{\circ} \mathrm{C}$ for $30 \mathrm{~min}$. Secondly, the active layer $\left(\mathrm{PTB7}: \mathrm{PC}_{71} \mathrm{BM}\right.$ or PTB7-Th:PC ${ }_{71} \mathrm{BM}$ ) was spin-cast from solution on PEDOT:PSS and then dried in vacuum. Thirdly, the CIL (LiF, TASiW-12 or PDINO) was deposited on the active layer. $\sim 1 \mathrm{~nm} \operatorname{LiF}$ was deposited on the active layer by thermal evaporation. $\sim 10-15$ nm TASiW-12 or $\sim 10 \mathrm{~nm}$ PDINO was deposited on the active layer by spin-coating. Finally, $100 \mathrm{~nm} \mathrm{Al} \mathrm{or} \mathrm{Ag} \mathrm{was} \mathrm{evaporated} \mathrm{as}$ a cathode. The structure of hole-only devices is ITO/PEDOT:PSS/ $\mathrm{PTB} 7: \mathrm{PC}_{71} \mathrm{BM} / \mathrm{CIL} / \mathrm{MoO}_{3} / \mathrm{Al}$. The structure of electron-only devices is ITO/Al/LiF/PTB7:PC ${ }_{71} \mathrm{BM} / \mathrm{CIL} / \mathrm{Al}$. The TASiW-12 film was deposited from methanol solution with a concentration of 
$0.5-2 \mathrm{mg} \mathrm{mL} \mathrm{m}^{-1}$ at $2000 \mathrm{rpm}$ for $60 \mathrm{~s}$ in a glove box under a $\mathrm{N}_{2}$ atmosphere.

\subsection{Characterization and measurements}

Current density-voltage characteristics of the devices were measured under a $\mathrm{N}_{2}$ atmosphere in the glove box by using a Keithley 2400 under illumination and in the dark. Solar cell performance was tested under 1 sun, AM 1.5G full spectrum solar simulator (Photo Emission Tech, model \#SS50AAA-GB) with an irradiation intensity of $100 \mathrm{~mW} \mathrm{~cm} \mathrm{~cm}^{-2}$ calibrated with a standard silicon photovoltaic traced to the National institute of metrology, China. EQE spectra were measured using a Q Test HIFINITY 5 (Crowntech Inc. USA) at room temperature in air. Capacitance-voltage characteristics of the devices were measured using an Agilent B1500A Semiconductor Device Analyzer with a CV module. AFM images were measured by using a S II Nanonaviprobe station $300 \mathrm{HV}$ in tapping-mode. SEM images were recorded with a JEOL FESEM 6700F electron microscope with a primary electron energy of $3 \mathrm{kV}$. The samples were sputtered with a thin layer of Pt before recording. The transient photocurrent of devices was measured by applying $355 \mathrm{~nm}$ laser pulses (Continuum Minilete TM Nd:YAG) with a frequency of $10 \mathrm{~Hz}$ and a low pulse energy to the short circuited devices in the dark. The photocurrent produced a transient voltage signal on a $50 \Omega$ load resistance, which was recorded by using an oscilloscope (Tektronix MSO 4054). XPS and UPS experiments were carried out using a XPS/UPS system equipped with a VG Scienta R3000 analyzer in ultrahigh vacuum with a base pressure of $1 \times 10^{-10}$ mbar. A monochromatic Al $(\mathrm{K} \alpha)$ X-ray source provides photons with $1486.6 \mathrm{eV}$ for XPS. A monochromatized He I $\alpha$ irradiation from a discharged lamp supplies photons with $21.22 \mathrm{eV}$ for UPS.

\section{Results and discussion}

\subsection{Molecular design and characterization of TASiW-12}

Synthesis of TASiW-12 can be referred from ref. 41 . It is worth noting that the synthesis procedures of TASiW-12 are simple, green, and of high-yield and low-cost. The detailed synthesis procedures are provided in the ESI. $\dagger$ As shown in Fig. 1c, four $\left[\left(\mathrm{C}_{8} \mathrm{H}_{17}\right)_{4} \mathrm{~N}\right]^{+}$and $\left[\mathrm{SiW}_{12} \mathrm{O}_{40}\right]^{4-}$ in TASiW-12 are bonded through electrostatic complexation to form a supramolecular complex. Four $\left[\left(\mathrm{C}_{8} \mathrm{H}_{17}\right)_{4} \mathrm{~N}\right]^{+}$groups can rearrange on the $\left[\mathrm{SiW}_{12} \mathrm{O}_{40}\right]^{4-}$ surface due to the electrostatic interaction. Compared to $\mathrm{H}_{4} \mathrm{SiW}_{12} \mathrm{O}_{40}$, TASiW-12 does not include protons, which avoids the acidic damage to the metal cathode and/or the active layer. Because the TASiW-12 film only has an absorption peak at 264 $\mathrm{nm}$ in an ultraviolet-visible absorption spectrum (Fig. S1 $\dagger$ ), there is no loss of light caused by TASiW-12 at 300-800 nm. Valence band versus vacuum level of the TASiW-12 film was obtained to be $7.0 \mathrm{eV}$ from ultraviolet photoemission spectrum (UPS) (Fig. S2 $\dagger$ ). Conduction band versus vacuum level which was equal to $2.9 \mathrm{eV}$ was calculated using the valence band and optical band gap. Consequently TASiW-12 is an n-type semiconductor with a conductivity of $8.76 \times 10^{-5} \mathrm{~S} \mathrm{~m}^{-1}$ (Fig. S3 $\dagger$ ). Compared to TOAB and $\mathrm{H}_{4} \mathrm{SiW}_{12} \mathrm{O}_{40}, \mathrm{TASiW}-12$ can form a better, denser and more uniform film on the PTB7:PC ${ }_{71} \mathrm{BM}$ due to the introduction of sixteen octyl chains as observed in the images of atom force microscopy (Fig. S4†) and scanning electron microscopy (Fig. S5 $\dagger$ ).

\subsection{Photovoltaic performance of the PSCs}

The effect of the $10 \mathrm{~nm}$ TASiW-12 film from methanol solution on device performance was first evaluated in the PSCs with the device architecture of ITO/PEDOT:PSS/PTB7:PC ${ }_{71} \mathrm{BM} / \mathrm{TASiW}-12 /$ $\mathrm{Al}$ (Fig. 1b). For comparison, LiF and PDINO (Fig. 1c) were also utilized as a CIL in the PSCs based on PTB7:PC 71 BM with $\mathrm{Al}$ as a cathode. In addition, the Al-only PSC without any CIL was used as a control device. Fig. 2a presents the current densityvoltage $(J-V)$ characteristics of the above 4 devices with various cathodes under AM 1.5G illumination at $100 \mathrm{~mW} \mathrm{~cm}{ }^{-2}$. The corresponding photovoltaic parameters derived from Fig. 2a are presented in Table 1 . The $V_{\mathrm{OC}}, J_{\mathrm{SC}}, \mathrm{FF}$ and PCE of all the devices with error bars are plotted in Fig. S6. $\uparrow$ In order to detect a discrepancy of $J_{\mathrm{SC}}$ which easily leads to an overvalued PCE, ${ }^{42}$ the external quantum efficiency (EQE) spectra of the devices from $300 \mathrm{~nm}$ to $800 \mathrm{~nm}$ were measured and are shown in Fig. $2 \mathrm{~b}$. $J_{\mathrm{SC}}^{\mathrm{EQE}}$ values calculated from the integration of the EQE spectra as listed in Table 1 are basically in agreement with the $J_{\mathrm{SC}}$ obtained from $J-V$ characteristics under illumination. In particular $J_{\mathrm{SC}}$ deviation from $J_{\mathrm{SC}}^{\mathrm{EQE}}$ for the device with TASiW-12 is below $5 \%$. It indicates that the $J_{\mathrm{SC}}$ measured for the cell with the TASiW-12 CIL is reliable and the PCE value ( 9\%) presented in Table 1 is not overvalued. Surprisingly, the best PCE of the device with TASiW-12 can reach 9.09\% which is not only higher than that of the control device but also higher than those of the other devices with $\mathrm{LiF}$ (8.79\%) and PDINO (8.76\%), respectively.
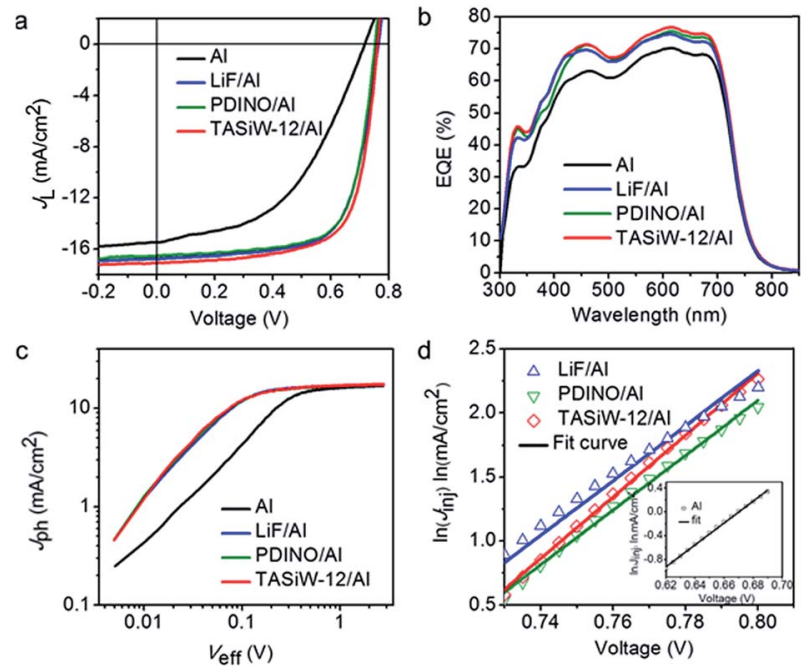

Fig. 2 (a) Current density versus applied voltage $(J-V)$ characteristics of the devices under $100 \mathrm{~mW} \mathrm{~cm}{ }^{-2}$ AM 1.5G illumination. (b) External quantum efficiency (EQE) spectra of the devices. (c) Photocurrent density versus effective voltage $\left(J_{\mathrm{ph}}-V_{\text {eff }}\right)$ characteristics of the devices under $100 \mathrm{~mW} \mathrm{~cm}{ }^{-2}$ AM $1.5 \mathrm{G}$ illumination. (d) Fitted dark injected current $J_{\text {inj }}$ versus applied voltage characteristics of the devices. Devices: PTB7:PC ${ }_{71}$ BM based PSCs with different cathodes. 
Table 1 Performances of the PSCs based on PTB7:PC 71 BM or PTB7-Th:PC ${ }_{71}$ BM with various cathodes

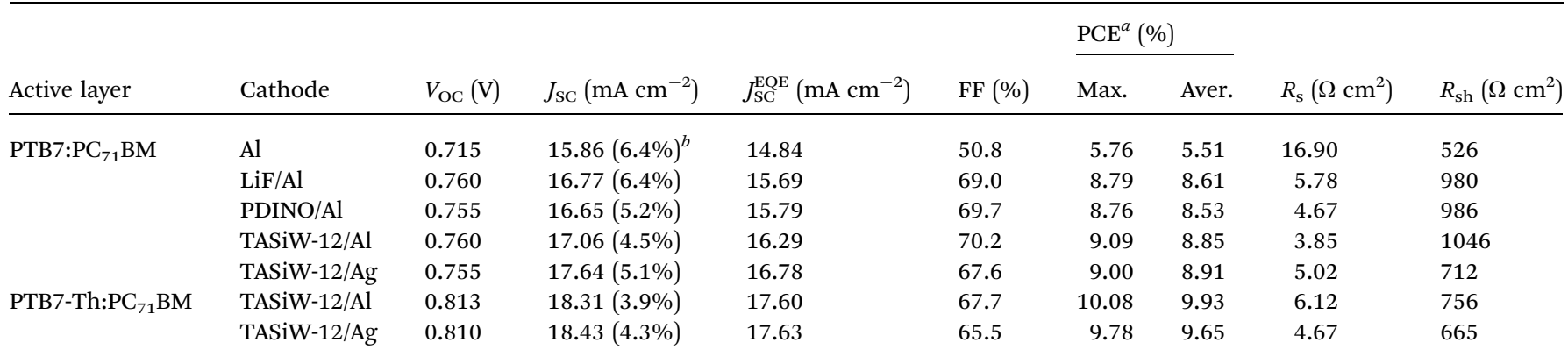

${ }^{a}$ At least 30 pixels were measured to obtain the average PCE values. ${ }^{b}$ All percentages in parentheses means $J_{\mathrm{SC}}$ deviation from $J_{\mathrm{SC}}^{\mathrm{EQE}}$.

Compared to the control device, all of the three CILs resulted in a simultaneous enhancement in $V_{\mathrm{OC}}, J_{\mathrm{SC}}$ and $\mathrm{FF}$. Moreover the device with TASiW-12 has the highest $J_{\mathrm{SC}}$ and FF accompanying the lowest series resistance $\left(R_{\mathrm{S}}\right)$ and the highest shunt resistance $\left(R_{\mathrm{sh}}\right)$ in the three devices with the CILs. In order to ensure the validity and repeatability of data, we measured at least 30 pixels (size $=2 \times 2 \mathrm{~mm}^{2}$ ) for all device configurations. The average PCE values of the devices with LiF, PDINO and TASiW12 are $8.61 \%, 8.53 \%$ and $8.85 \%$, respectively. The PSCs with TASiW-12 showed a better device stability because $88 \%$ of initial PCE could be retained after 500 hours (Fig. S7 and Table S1†).

The best performance of the device with TASiW-12 is supported by the dependence of the photocurrent density $\left(J_{\mathrm{ph}}\right)$ on the effective voltage $\left(V_{\text {eff }}\right)$, where $J_{\mathrm{ph}}=J_{\mathrm{L}}-J_{\mathrm{D}}\left(J_{\mathrm{L}}\right.$ and $J_{\mathrm{D}}$ are the current density under illumination (Fig. 2a) and dark (Fig. S8 $\dagger$ ) conditions, respectively) and $V_{\text {eff }}=V_{0}-V\left(V_{0}\right.$ is the voltage at $J_{\mathrm{ph}}$ $=0$ and $V$ the is applied voltage) as shown in Fig. 2c. ${ }^{43}$ At sufficiently high $V_{\text {eff }}$, the photocurrent is saturated without recombination $\left(J_{\mathrm{ph} \text {,sat }}\right)$. The $J_{\mathrm{ph}} / J_{\mathrm{ph} \text {,sat }}$ ratio is the product of exciton dissociation and charge collection probabilities. Under short-circuit conditions, the control device has a $J_{\mathrm{ph}, \mathrm{sc}} / J_{\mathrm{ph} \text {,sat }}$ ratio of $93.1 \%$ while $J_{\mathrm{ph}, \mathrm{sc}} / J_{\mathrm{ph} \text {,sat }}$ ratios of the PSCs with $\mathrm{LiF}$, PDINO and TASiW-12 are 95.9\%, 95.1\% and 97.3\%, respectively. It implies that the PSC with TASiW-12 has better exciton dissociation. Under maximum power output conditions, the PSC with TASiW-12 also shows a higher $J_{\mathrm{ph}, \max } / J_{\mathrm{ph} \text {,sat }}$ ratio $(83.8 \%)$ than other PSCs $\left(J_{\mathrm{ph} \text {,max }} / J_{\mathrm{ph} \text {,sat }}=70.0 \%\right.$ for bare $\mathrm{Al}$, $82.9 \%$ for $\mathrm{LiF}$ and $83.7 \%$ for PDINO). It suggests that the TASiW12 based PSC exhibits enhanced charge extraction and collection. Accordingly we infer that the best photovoltaic performance of the TASiW-12 based PSC should originate from not only enhanced exciton dissociation but also reduced bimolecular recombination. Diode ideality factor $n$ (departure from unity) is an important factor to characterize trap-assisted and tail state recombination. $n$ can be extracted from the dark $J-V$ curve based on eqn (S1). $\dagger^{\mathbf{4 4}}$ The $n$ values of the four PSCs have been calculated from the linear slopes in Fig. 2d derived from the dark $J-V$ curves (Fig. S8 $\dagger$ ). Compared to the Al-only PSC $(n=$ 2.1), the $n$ values of the PSCs with LiF and PDINO are 1.82 while the $n$ of the PSC with TASiW-12 is 1.61. These results indicate that there is less trap-assisted charge carrier recombination during charge transport using TASiW-12 than LiF and PDINO.
More detailed information about the charge recombination dynamics and the charge extraction process was probed via transient photocurrent (TPC) measurements (Fig. S9†). ${ }^{45,46}$ So the charge carrier extraction time $(\tau)$ of the PSCs are $1.73 \mu$ s for Al-only, $0.96 \mu \mathrm{s}$ for $\mathrm{LiF}, 0.97 \mu \mathrm{s}$ for PDINO and $0.94 \mu \mathrm{s}$ for TASiW-12 derived from Fig. S9a. $\dagger$ The shortest $\tau$ for the PSC with TASiW-12 may be due to the fewest electrically active traps, which is consistent with the lowest $n$ (1.61). In addition, we also examined the amount of the extracted charges by comparing the area below transient photocurrent curves without normalization. As shown in Fig. S9b $\uparrow$ in the ESI, $\uparrow$ it is obvious that the amount of the extracted charges from the device based on the TASiW-12 is higher than the amount of the extracted charges from other 3 devices. Accordingly higher charge extraction efficiency was achieved in the PSC with TASiW-12, which led to a higher FF. Compared to Al-only control device, the PSCs with the CILs show much higher FF values as listed in Table 1. In particular the FF of the PSC with TASiW-12 reaches $70.2 \%$. It implies that TASiW-12 as a CIL effectively improved the charge transport ability. In order to confirm the improved charge carrier transport, the mobilities of electron and hole were measured in the electron-only (Fig. S10a $\dagger$ ) and hole-only (Fig. S10b $\dagger$ ) devices using the space charge limited current method according to eqn (S2). $\dagger^{47}$ The mobilities of electron and hole for Al-only devices are $2.74 \times 10^{-5} \mathrm{~cm}^{2} \mathrm{~V}^{-1} \mathrm{~s}^{-1}$ and $2.71 \times$ $10^{-5} \mathrm{~cm}^{2} \mathrm{~V}^{-1} \mathrm{~s}^{-1}$, respectively. However, the mobilities of electron for the devices with LiF, PDINO and TASiW-12 increased to $3.56 \times 10^{-4} \mathrm{~cm}^{2} \mathrm{~V}^{-1} \mathrm{~s}^{-1}, 3.15 \times 10^{-4} \mathrm{~cm}^{2} \mathrm{~V}^{-1} \mathrm{~s}^{-1}$ and $4.48 \times 10^{-3} \mathrm{~cm}^{2} \mathrm{~V}^{-1} \mathrm{~s}^{-1}$, respectively. At the same time the mobilities of hole for the devices with LiF, PDINO and TASiW-12 increased to $3.56 \times 10^{-4} \mathrm{~cm}^{2} \mathrm{~V}^{-1} \mathrm{~s}^{-1}, 5.55 \times 10^{-4} \mathrm{~cm}^{2} \mathrm{~V}^{-1} \mathrm{~s}^{-1}$ and $7.03 \times 10^{-4} \mathrm{~cm}^{2} \mathrm{~V}^{-1} \mathrm{~s}^{-1}$, respectively. The enhanced electron and hole mobilities are believed to contribute to the improved $J_{\mathrm{SC}}$ and FF in the PSC with TASiW-12.

\subsection{Capacitance-voltage characteristics of the PSCs}

As shown in Table 1, the $V_{\text {OC }}$ of the device with TASiW-12 is almost the same as the device with LiF and slightly higher than the device with PDINO, which can be explained by a WF change of Al modified by various CIL materials in the UPS measurements (Fig. S11†). UPS results demonstrated that WF values of 
$\mathrm{Al}$ covered by $\mathrm{LiF}$ and TASiW-12 were $\sim 3.3 \mathrm{eV}$ while the WF of Al covered by PDINO was $\sim 3.6 \mathrm{eV}$. The built-in voltage $\left(V_{\mathrm{bi}}\right)$ influences the internal electric field in the PSCs and gives the upper limit for the $V_{\text {OC }}$ provided that the WF difference of electrodes is larger than the donor HOMO-acceptor LUMO offset in the PSCs. Thus the increased $V_{\text {OC }}$ should be consistent with the increased $V_{\mathrm{bi}}$ across the devices with the CIL. In order to confirm this speculation, we performed capacitance $(C)$ versus voltage $(V)$ measurements of the four devices with various cathodes. Fig. 3a-d show $(C / A)^{-2}-V$ curves of the devices in the dark. The value of $V_{\mathrm{bi}}$ is estimated by using the Mott-Schottky relationship (eqn (1)) as follows.

$$
\frac{1}{C^{2}}=\frac{2\left(V_{\mathrm{bi}}-V\right)}{q \varepsilon_{0} \varepsilon_{\mathrm{r}} N A^{2}}
$$

where $V_{\mathrm{bi}}$ is the flat-band potential, which is obtained from the intercept of linear $(C / A)^{-2}-V, q$ accounts for the elementary charge, $\varepsilon_{0}$ is the dielectric constant of vacuum, $\varepsilon_{\mathrm{r}}$ represents the relative dielectric constant of the semiconductor and $A$ is the active area of the device. ${ }^{\mathbf{4 8 , 4 9}}$ The $V_{\mathrm{bi}}$ values from eqn (1) are $0.73 \mathrm{~V}$ for the control device, $0.80 \mathrm{~V}$ for the device with $\mathrm{LiF}$, $0.80 \mathrm{~V}$ for the device with PDINO and $0.81 \mathrm{~V}$ for the device with TASiW-12. Apparently the $V_{\mathrm{bi}}$ of the device with TASiW-12 is slightly higher than that of the other two devices with the CILs, which rationalizes its slightly higher $V_{\mathrm{OC}}(0.76 \mathrm{~V})$.

According to eqn (1), charge carrier density $N$ can be derived from the slope of linear $(C / A)^{-2}-V$ (Fig. 3a-d). The incorporation of CIL resulted in an increase of $N$ from $1.66 \times 10^{16} / \mathrm{cm}^{3}$ for Alonly to $2.59 \times 10^{16} / \mathrm{cm}^{3}$ for $\mathrm{LiF} / \mathrm{Al}, 2.65 \times 10^{16} / \mathrm{cm}^{3}$ for PDINO/Al and $4.68 \times 10^{16} / \mathrm{cm}^{3}$ for TASiW-12/Al, respectively. Obviously, there is a higher charge carrier density in the device with TASiW-12 than other devices so that the PSC with TASiW-12 demonstrated a higher $J_{\text {SC }}$.
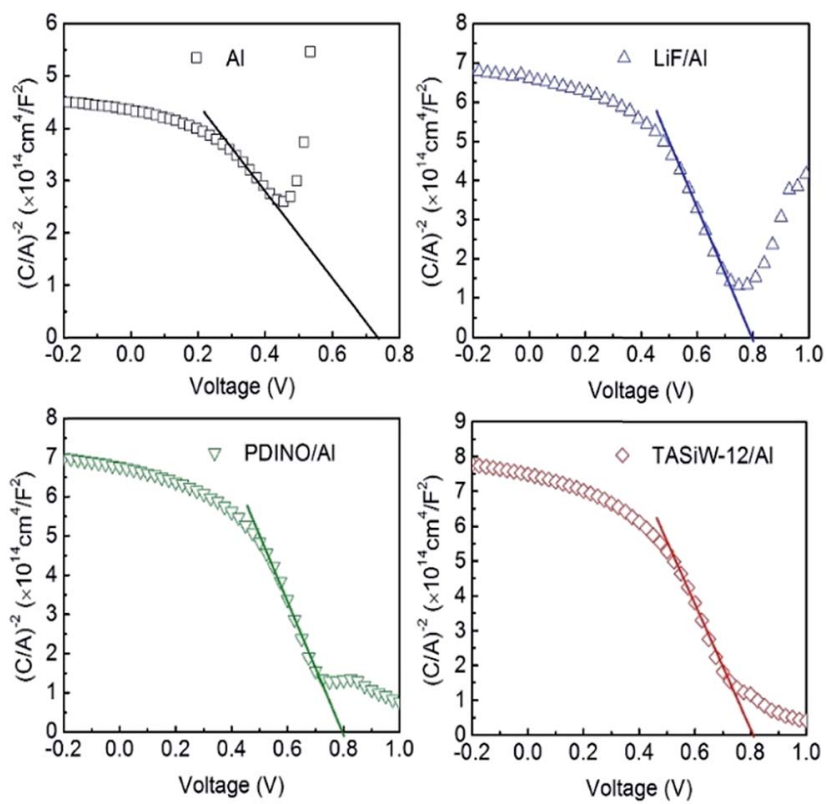

Fig. 3 Mott-Schottky plots of capacitance versus voltage of PTB7:PC ${ }_{71}$ BM based PSCs with different cathodes in the dark.

\subsection{Universality of TASiW-12 as a CIL in the PSCs}

In order to prove that TASiW-12 is a universal CIL for different metal cathodes and different active layers, we further checked its performance in $\mathrm{PTB} 7: \mathrm{PC}_{71} \mathrm{BM}$ based devices with $\mathrm{Ag}$ as a cathode and PTB7-Th:PC ${ }_{71} \mathrm{BM}$ based devices with $\mathrm{Al}$ or $\mathrm{Ag}$ as a cathode. The $J-V$ characteristics of the devices under $100 \mathrm{~mW}$ $\mathrm{cm}^{-2}$ AM 1.5G irradiation are presented in Fig. $4 \mathrm{a}$ and $\mathrm{b}$ and EQE spectra of the devices are shown in Fig. 4c and d. The performance parameters are summarized in Table 1. As we expected, the PCE can still reach $9.00 \%$ when $\mathrm{Ag}$ replaced $\mathrm{Al}$ as a cathode in the PTB7:PC ${ }_{71} \mathrm{BM}$ based PSC with $15 \mathrm{~nm}$ TASiW-12. When $10 \mathrm{~nm}$ TASiW-12 for Al cathode or $15 \mathrm{~nm}$ TASiW-12 for Ag cathode was used in the PTB7-Th:PC ${ }_{71} \mathrm{BM}$ system, the PCE values of the PSCs can be enhanced to $10.08 \%$ and $9.78 \%$, respectively. In order to further confirm such a high PCE of over 10\%, encapsulated PTB7-Th:PC ${ }_{71} \mathrm{BM}$ based PSCs with TASiW12/Al were sent to the National institute of metrology, China for certification. A certified PCE of $9.49 \%$ was obtained with a $J_{\text {SC }}$ of $18.20 \mathrm{~mA} \mathrm{~cm}^{-2}$, a $V_{\text {OC }}$ of $0.82 \mathrm{~V}$ and a FF of $64 \%$ (Fig. S12 $\dagger$ ). The certified PCE result is $4.4 \%$ lower than the average value (9.93\%) in our lab mainly due to the decrease of $\mathrm{FF}$, which can be attributed to non-ideal cell encapsulation. ${ }^{6,28}$ In addition, we also examined its function as a CIL in the PSCs based on PCDTBT:PC ${ }_{71}$ BM. As shown in Fig. S13 and Table S2, $\uparrow$ the incorporation of TASiW-12 resulted in improved PCE values from $4.3 \%$ of the control device without CIL to $7.15 \%$ with $\mathrm{Al}$ as the cathode and from $4.73 \%$ of the control device to $7.17 \%$ with $\mathrm{Ag}$ as the cathode.

\subsection{Working mechanism of TASiW-12 as a CIL in the PSCs}

In order to investigate the working mechanism of TASiW-12 as a CIL in the PSCs with $\mathrm{Al}$ or Ag as a cathode, we carried out XPS
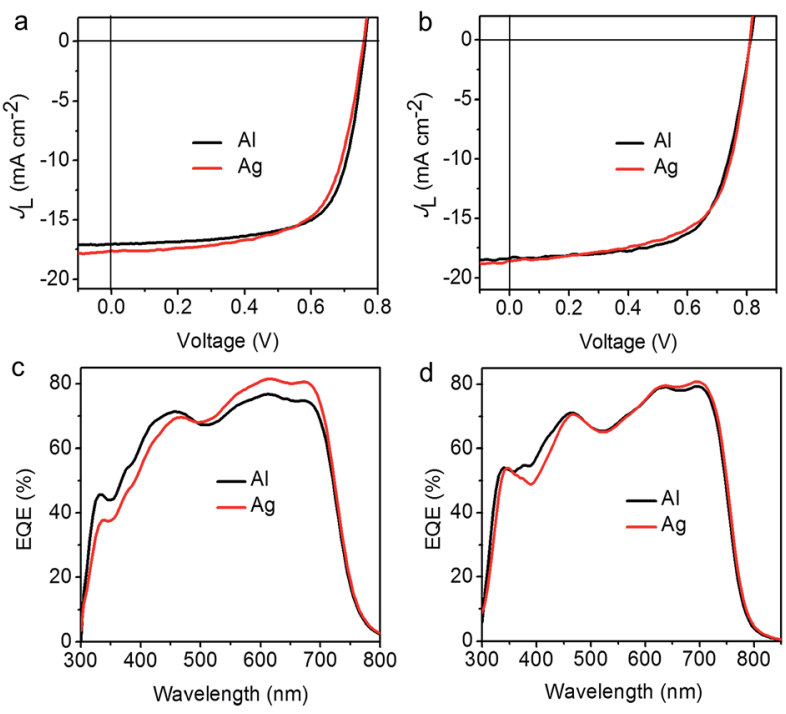

Fig. 4 Current density versus applied voltage $(J-V)$ characteristics of the PTB7:PC ${ }_{71} \mathrm{BM}(\mathrm{a})$ or PTB7-Th:PC ${ }_{71} \mathrm{BM}(\mathrm{b})$ based PSCs with TASiW12/Al or TASiW-12/Ag under $100 \mathrm{~mW} \mathrm{~cm}^{-2} \mathrm{AM} 1.5 \mathrm{G}$ illumination. External quantum efficiency (EQE) spectra of $P T B 7: P C_{71} B M$ (c) or PTB7-Th:PC ${ }_{71} \mathrm{BM}$ (d) based PSCs with TASiW-12/Al or TASiW-12/Ag. 
and UPS measurements for the Al/TASiW-12 interface and the Ag/TASiW-12 interface. When $10 \mathrm{~nm}$ TASiW-12 was deposited on the $\mathrm{Al}$ surface slightly oxidized $\left(\mathrm{Al} / \mathrm{AlO}_{x}\right)$, the $\mathrm{Al} 2 \mathrm{p}$ core level XPS spectrum presented a higher peak intensity at $75.4 \mathrm{eV}$ assigned to $\mathrm{Al}^{3+}$ than $\mathrm{Al} / \mathrm{AlO}_{x}$ as shown in Fig. 5a. Compared to bulk TASiW-12, two new peaks at $34.7 \mathrm{eV}$ and $36.8 \mathrm{eV}$ assigned to $\mathrm{W}_{4} \mathrm{f}_{7 / 2}$ and $\mathrm{W}_{4} \mathrm{f}_{5 / 2}$ of $\mathrm{W}^{5+}$ appeared except the two peaks at $36.0 \mathrm{eV}$ and $38.1 \mathrm{eV}$ corresponding to $\mathrm{W} 4 \mathrm{f}_{7 / 2}$ and $\mathrm{W} 4 \mathrm{f}_{5 / 2}$ of $\mathrm{W}^{6+}$ for the fitted W4f XPS spectrum of $10 \mathrm{~nm}$ TASiW-12 on $\mathrm{Al} / \mathrm{AlO}_{x}$ as shown in Fig. 5b. It means that the $\mathrm{Al}$ surface was further oxidized and $\mathrm{W}^{6+}$ was partially reduced into $\mathrm{W}^{5+}$ in the TASiW12. Fig. $5 \mathrm{c}$ presents the O1s core level spectrum of $10 \mathrm{~nm}$ TASiW12 on the $\mathrm{Al} / \mathrm{AlO}_{x}$ fitted with four chemical state components, which are the two peaks at $530.8 \mathrm{eV}$ and $532.3 \mathrm{eV}$ from bulk TASiW-12 (inset), the peak at $531.8 \mathrm{eV}$ from $\mathrm{Al}_{2} \mathrm{O}_{3}$ (ref. 50) and a new peak at $533.7 \mathrm{eV}$. Obviously the new peak originates from the interaction of the terminal $\mathrm{O}$ in the TASiW-12 and $\mathrm{Al}$ at the $\mathrm{Al} / \mathrm{TASiW}-12$ interface. It is clear that there exist a strong electron transfer from $\mathrm{Al}$ to TASiW-12 through $\mathrm{W}-\mathrm{O}-\mathrm{Al}$ contact at the Al/TASiW-12 interface. Similarly Ag3d (Fig. S14a $\dagger$ ), W4f (Fig. S14b $\dagger$ ) and O1s (Fig. S14c $\dagger$ ) XPS spectra of 15 nm TASiW-12 on the Ag demonstrate that there exists a weaker electron transfer from Ag to TASiW-12 through W-O-Ag contact at the $\mathrm{Ag} / \mathrm{TASiW}-12$ interface because $\mathrm{Ag}$ is a nobler metal than $\mathrm{Al}$. Compared to the bulk TASiW-12, N1s core level spectra of $10 \mathrm{~nm}$ TASiW-12 on the Al (Fig. 5d) and $15 \mathrm{~nm}$ TASiW-12 on the $\mathrm{Ag}$ (Fig. S14d $\dagger$ ) shifted towards the lower binding energy,
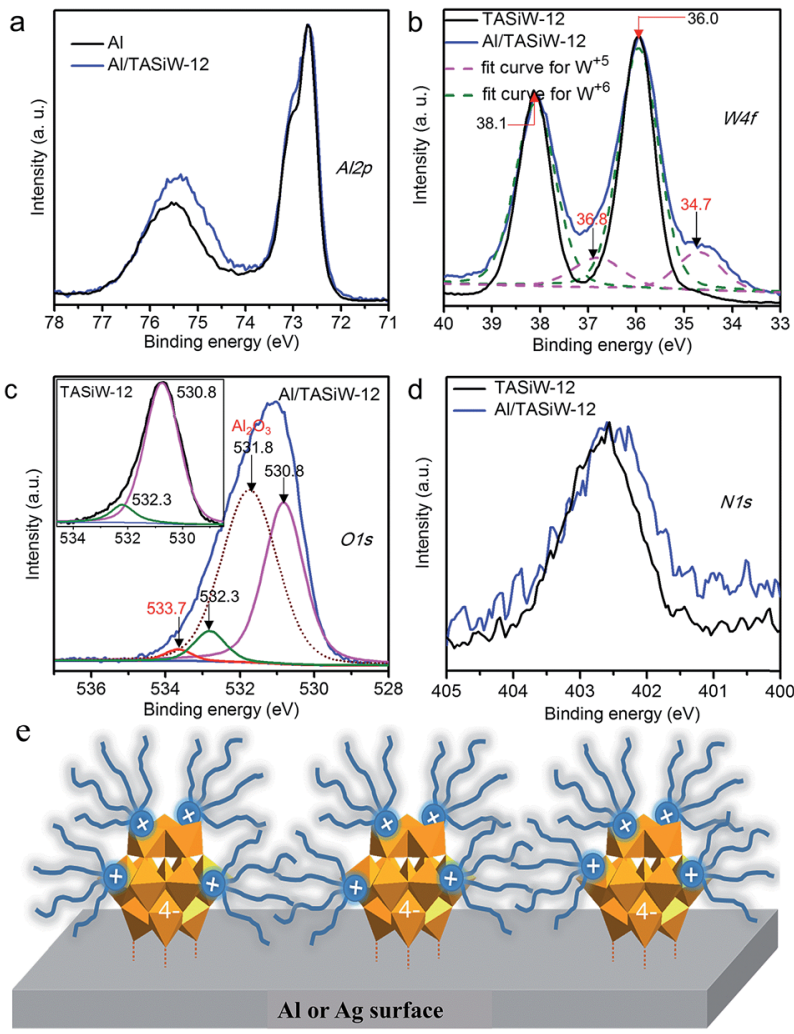

Fig. 5 (a) Al2p, (b) W4f, (c) O1s and (d) N1s core-level XPS spectra of Al, and Al covered by $8 \mathrm{~nm}$ TASiW-12 and $40 \mathrm{~nm}$ TASiW-12 on ITO. (e) Self-assembly diagram of TASiW-12 on the Al or Ag surface. indicating that the $\mathrm{O}$ concentration around $\left[\left(\mathrm{C}_{8} \mathrm{H}_{17}\right)_{4} \mathrm{~N}\right]^{+}$ decreased. Therefore we infer that the $\left[\mathrm{SiW}_{12} \mathrm{O}_{40}\right]^{4-}$ was strongly adsorbed on the metal surfaces due to the formation of a chemisorption bond between the metals and terminal $\mathrm{O}$ atoms of the $\left[\mathrm{SiW}_{12} \mathrm{O}_{40}\right]^{4-}$ in TASiW-12. ${ }^{51}$ At the same time four $\left[\left(\mathrm{C}_{8} \mathrm{H}_{17}\right)_{4} \mathrm{~N}\right]^{+}$groups were pushed away from the metal surface due to the polarity difference between the alkyl chains of $\left[\left(\mathrm{C}_{8} \mathrm{H}_{17}\right)_{4} \mathrm{~N}\right]^{+}$groups and the metal surface. ${ }^{41}$ As a result, $\left[\mathrm{SiW}_{12} \mathrm{O}_{40}\right]^{4-}$ is close to the metal surface and four $\left[\left(\mathrm{C}_{8} \mathrm{H}_{17}\right)_{4} \mathrm{~N}\right]^{+}$ groups are far away from the metal surface as shown in Fig. 5e. Such a direction of the interface dipole is favourable to reduce the WF of the metal cathode. In fact TASiW-12 has changed the $\mathrm{WF}$ of $\mathrm{Al}$ from $4.2 \mathrm{eV}$ to $3.2 \mathrm{eV}$ (Fig. 6a) and the WF of $\mathrm{Ag}$ from $4.6 \mathrm{eV}$ to $3.9 \mathrm{eV}$ in the UPS measurements (Fig. 6b). The electron transfer state can be further confirmed from the valence band spectra of three TASiW-12 films ( $8 \mathrm{~nm}, 15 \mathrm{~nm}$ and $20 \mathrm{~nm})$ on Al or Ag. A new peak around $1.1 \mathrm{eV}$ corresponding to an electron transfer state has appeared in the energy gap region of the valence band spectra of $8 \mathrm{~nm}, 15 \mathrm{~nm}$ and $20 \mathrm{~nm}$ TASiW-12 on $\mathrm{Al}$ (inset of Fig. 6a). A new peak around $1.1 \mathrm{eV}$ can also be found when the thickness of TASiW-12 on Ag is over $15 \mathrm{~nm}$ because Ag is less reactive than $\mathrm{Al}$ (inset of Fig. 6b). However the peak around $1.1 \mathrm{eV}$ disappeared when the TASiW-12 film is thicker than $30 \mathrm{~nm}$ whether on $\mathrm{Al}$ or on $\mathrm{Ag}$. It demonstrates that the charge transfer from the metal to TASiW-12 occurs at the metal/ TASiW-12 interface region. For comparison, we additionally deposited $8 \mathrm{~nm}, 15 \mathrm{~nm}$ and $20 \mathrm{~nm}$ TASiW-12 on ITO. No peak is

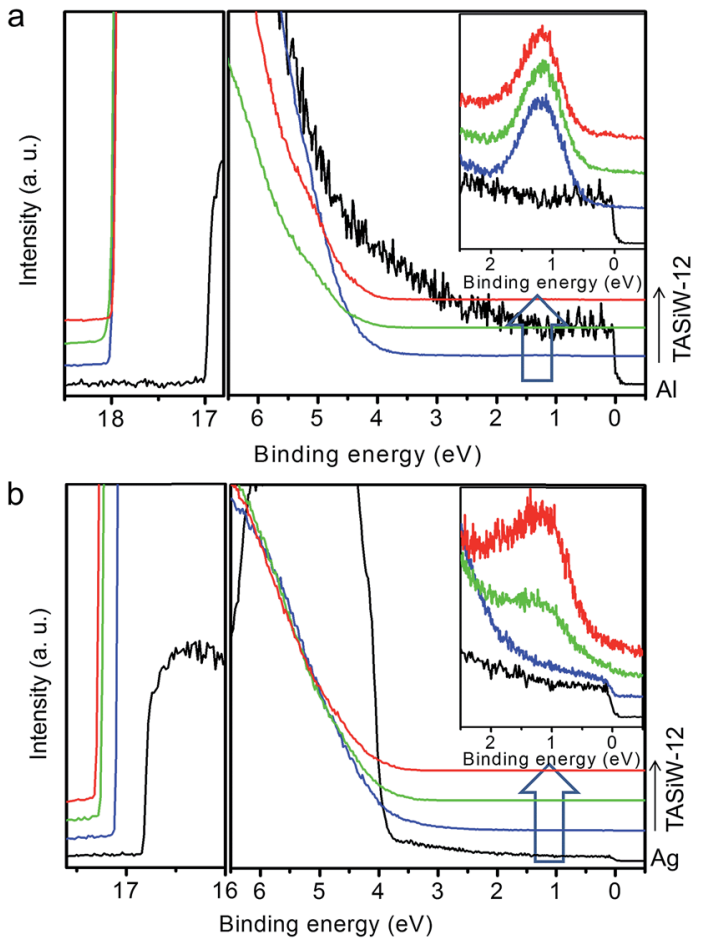

Fig. 6 (a) UPS spectra of Al (black line), $8 \mathrm{~nm}$ (blue line), $15 \mathrm{~nm}$ (green line) and $20 \mathrm{~nm}$ (red line) TASiW-12 on Al. (b) UPS spectra of Ag (black line), $8 \mathrm{~nm}$ (blue line), $15 \mathrm{~nm}$ (green line) and $20 \mathrm{~nm}$ (red line) TASiW-12 on $\mathrm{Ag}$. Insets show the valence band spectra blown up from -0.5 to $2.5 \mathrm{eV}$. 
observed in the valence band spectra from $-0.5 \mathrm{eV}$ to $2.5 \mathrm{eV}$ (inset of Fig. S15 $\dagger$ ). Apparently an n-type doping of TASiW-12 really happened at the interface upon contact with the metals (Al, Ag, etc.), leading to an increase of electron density in the TASiW-12. These combined XPS and UPS results clearly demonstrate that a good CIL not only decreases the WF of the metal cathode due to a negative interfacial dipole but also can be doped by a metal cathode or other electron donors due to the electron-accepting nature of the CIL. Such a doping of CILS usually can give rise to simultaneous enhancements of electron density and mobility. As a result, the conductivity of the CIL film can be increased by several orders of magnitude. ${ }^{52-55}$ Therefore our findings provide insights into working mechanism of the CILs simultaneously improving $V_{\mathrm{OC}}, J_{\mathrm{SC}}$ and FF.

\section{Conclusions}

Environment-friendly, low cost and transparent n-type semiconductor TASiW-12 has been synthesized and applied as a universal CIL in PSCs. When TASiW-12 was utilized as a CIL in the PTB7:PC ${ }_{71} \mathrm{BM}$ based PSCs, the PCEs can reach 9.1\% with $\mathrm{Al}$ as a cathode and $9.0 \%$ with $\mathrm{Ag}$ as a cathode. Similarly, TASiW-12 can improve the PCE values of the PTB7-Th:PC ${ }_{71} \mathrm{BM}$ based PSCs with $\mathrm{Al}$ and $\mathrm{Ag}$ to $10.1 \%$ and $9.8 \%$, respectively. Combined measurements of $J-V$ characteristics, transient photocurrent, charge carrier mobility and $C-V$ characteristics demonstrated that the incorporation of TASiW-12 increased the built-in potential, charge carrier density and mobility, and accelerated the charge carrier extraction in the PSCs. Finally the working mechanism of TASiW-12 as a CIL in the conventional PSCs was revealed by XPS and UPS measurements of the metal/TASiW-12 interface. Our findings suggest that TASiW-12 as a good CIL not only decreased the WF of the cathode but also could be n-doped upon contact with the metal cathodes ( $\mathrm{Al}$ and $\mathrm{Ag}$ ), which provide insights into the working mechanism of the CILS simultaneously improving the $V_{\mathrm{OC}}, J_{\mathrm{SC}}$ and FF. These results indicate that the surfactant-encapsulated POM complexes are competitive CIL materials for environment-friendly, low cost and large-area roll to roll production of PSCs.

\section{Acknowledgements}

This work was supported by grants from the National Basic Research Program of China (2014CB643505) and the Natural Science Foundation of China (51273077).

\section{Notes and references}

1 Y. H. Liu, J. B. Zhao, Z. K. Li, C. Mu, W. Ma, H. W. Hu, K. Jiang, H. R. Lin, H. Ade and H. Yan, Nat. Commun., 2014, 5, 5293.

2 V. Vohra, K. Kawashima, T. Kakara, T. Koganezawa, I. Osaka,

K. Takimiya and H. Murata, Nat. Photonics, 2015, 9, 403.

3 S. Q. Zhang, L. Ye, W. C. Zhao, B. Yang, Q. Wang and J. H. Hou, Sci. China: Chem., 2015, 58, 248.

4 W. C. Zhao, D. P. Qian, S. Q. Zhang, S. S. Li, O. Inganäs, F. Gao and J. H. Hou, Adv. Mater., 2016, 28, 4734.
5 H. Fei, Sci. China: Chem., 2015, 58, 190.

6 Z. C. He, C. M. Zhong, S. J. Su, M. Xu, H. B. Wu and Y. Cao, Nat. Photonics, 2012, 6, 591.

7 C. Gu, Y. C. Chen, Z. B. Zhang, S. F. Xue, S. H. Sun, K. Zhang, C. M. Zhong, H. H. Zhang, Y. Lv, F. H. Li, F. Huang and Y. G. Ma, Adv. Energy Mater., 2014, 4, 1301771.

8 M. L. Lv, S. S. Li, J. J. Jasieniak, J. H. Hou, J. Zhu, Z. A. Tan, S. E. Watkins, Y. F. Li and X. W. Chen, Adv. Mater., 2013, 25, 6889.

9 Z. A. Tan, W. Q. Zhang, Z. G. Zhang, D. P. Qian, Y. Huang, J. H. Hou and Y. F. Li, Adv. Mater., 2012, 24, 1476.

10 Z. H. Wu, C. Sun, S. Dong, X. F. Jiang, S. P. Wu, H. B. Wu, H. L. Yip, F. Huang and Y. Cao, J. Am. Chem. Soc., 2016, 138, 2004.

11 J. H. Seo, A. Gutacker, Y. M. Sun, H. B. Wu, F. Huang, Y. Cao, U. Scherf, A. J. Heeger and G. C. Bazan, J. Am. Chem. Soc., 2011, 133, 8416.

12 S. H. Liao, Y. L. Li, T. H. Jen, Y. S. Cheng and S. A. Chen, J. Am. Chem. Soc., 2012, 134, 14271.

13 Y. Zhao, Z. Y. Xie, C. J. Qin, Y. Qu, Y. H. Geng and L. X. Wang, Sol. Energy Mater. Sol. Cells, 2009, 93, 604.

14 Z. C. He, C. M. Zhong, X. Huang, W. Y. Wong, H. B. Wu, L. W. Chen, S. J. Su and Y. Cao, Adv. Mater., 2011, 23, 4636. 15 Y. J. Cheng, C. H. Hsieh, Y. J. He, C. S. Hsu and Y. F. Li, J. Am. Chem. Soc., 2010, 132, 17381.

16 Z. A. Page, Y. Liu, V. V. Duzhko, T. P. Russell and T. Emrick, Science, 2014, 346, 441.

17 Z. G. Zhang, B. Y. Qi, Z. W. Jin, D. Chi, Z. Qi, Y. F. Li and J. Z. Wang, Energy Environ. Sci., 2014, 7, 1966.

18 T. H. Reilly, A. W. Hains, H. Y. Chen and B. A. Gregg, Adv. Energy Mater., 2012, 2, 455.

19 T. V. Pho, H. Kim, J. H. Seo, A. J. Heeger and F. Wudl, Adv. Funct. Mater., 2011, 21, 4338.

20 W. P. Chen, J. J. Lv, J. X. Han, Y. C. Chen, T. Jia, F. H. Li and Y. Wang, J. Mater. Chem. A, 2016, 4, 2169.

21 T. Jia, W. L. Zhou, Y. C. Chen, J. X. Han, L. Wang, F. H. Li and Y. Wang, J. Mater. Chem. A, 2015, 3, 4547.

22 X. Cheng, S. H. Sun, Y. C. Chen, Y. J. Gao, L. Ai, T. Jia, F. H. Li and Y. Wang, J. Mater. Chem. A, 2014, 2, 12484.

23 Q. Mei, C. H. Li, X. Gong, H. Lu, E. Q. Jin, C. Du, Z. Lu, L. Jiang, X. Y. Meng, C. R. Wang and Z. S. Bo, ACS Appl. Mater. Interfaces, 2013, 5, 8076.

24 F. W. Zhao, Z. Wang, J. Q. Zhang, X. W. Zhu, Y. J. Zhang, J. Fang, D. Deng, Z. X. Wei, Y. F. Li, L. Jiang and C. R. Wang, Adv. Energy Mater., 2016, 6, 1502120.

25 M. Vasilopoulou, D. G. Georgiadou, A. M. Douvas, A. Soultati, V. Constantoudis, D. Davazoglou, S. Gardelis, L. C. Palilis, M. Fakis, S. Kennou, T. Lazarides, A. G. Coutsolelos and P. Argitis, J. Mater. Chem. A, 2014, 2, 182.

26 Z. G. Zhang, H. Li, B. Y. Qi, D. Chi, Z. W. Jin, Z. Qi, J. H. Hou, Y. F. Li and J. Z. Wang, J. Mater. Chem. A, 2013, 1, 9624.

27 C. Z. Li, C. Y. Chang, Y. Zang, H. X. Ju, C. C. Chueh, P. W. Liang, N. Cho, D. S. Ginger and A. K. Y. Jen, Adv Mater., 2014, 26, 6262.

28 X. H. Ouyang, R. X. Peng, L. Ai, X. Y. Zhang and Z. Y. Ge, Nat. Photonics, 2015, 9, 520. 
29 C. H. Wu, C. Y. Chin, T. Y. Chen, S. N. Hsieh, C. H. Lee, T. F. Guo, A. K. Y. Jen and T. C. Wen, J. Mater. Chem. A, 2013, 1, 2582.

30 M. T. Pope and A. Muller, Angew. Chem., Int. Ed., 1991, 30, 34.

31 D. Velessiotis, N. Glezos and V. Ioannou-Sougleridis, J. Appl. Phys., 2005, 98, 084503.

32 A. M. Douvas, E. Makarona, N. Glezos, P. Argitis, J. A. Mielczarski and E. Mielczarski, ACS Nano, 2008, 2, 733.

33 L. C. Palilis, M. Vasilopoulou, D. G. Georgiadou and P. Argitis, Org. Electron., 2011, 11, 887.

34 S. S. Xu, Y. H. Wang, Y. Zhao, W. L. Chen, J. B. Wang, L. F. He, Z. M. Su, E. B. Wang and Z. H. Kang, J. Mater. Chem. A, 2016, 4, 14025.

35 M. Vasilopoulou, E. Polydorou, A. M. Douvas, L. C. Palilis, S. Kennou and P. Argitis, Energy Environ. Sci., 2015, 8, 2448.

36 L. C. Palilis, M. Vasilopoulou, A. M. Douvas, D. G. Georgiadou, S. Kennou, N. A. Stathopoulos, V. Constantoudis and P. Argitis, Sol. Energy Mater. Sol. Cells, 2013, 114, 205.

37 M. Vasilopoulou, A. M. Douvas, L. C. Palilis, S. Kennou and P. Argitis, J. Am. Chem. Soc., 2015, 137, 6844.

38 L. Nian, W. Q. Zhang, N. Zhu, L. L. Liu, Z. Q. Xie, H. B. Wu, F. Würthner and Y. G. Ma, J. Am. Chem. Soc., 2015, 137, 6995.

39 L. Nian, Z. H. Chen, S. Herbst, Q. Y. Li, C. Z. Yu, F. H. Li, F. Würthner, J. W. Chen, Z. Q. Xie and Y. G. Ma, Adv. Mater., 2016, 28, 7521.

40 X. H. Liu, X. D. Li, Y. Li, C. J. Song, L. P. Zhu, W. J. Zhang, H. Q. Wang and J. F. Fang, Adv. Mater., 2016, 28, 7405.

41 H. L. Li, H. Sun, W. Qi, M. Xu and L. X. Wu, Angew. Chem., Int. Ed., 2007, 46, 1300.

42 E. Zimmermann, P. Ehrenreich, T. Pfadler, J. A. Dorman, J. Weickert and L. Schmidt-Mende, Nat. Photonics, 2014, 8, 669.
43 S. R. Cowan, R. A. Street, S. Cho and A. J. Heeger, Phys. Rev. B: Condens. Matter Mater. Phys., 2011, 83, 035205.

44 Q. Zhang, B. Kan, F. Liu, G. K. Long, X. J. Wan, X. Q. Chen, Y. Zuo, W. Ni, H. J. Zhang, M. M. Li, Z. C. Hu, F. Huang, Y. Cao, Z. Q. Liang, M. T. Zhang, T. P. Russell and Y. S. Chen, Nat. Photonics, 2015, 9, 35.

45 F. Gao, Z. Li, J. Wang, A. Rao, I. A. Howard, A. Abrusci, S. Massip, C. R. McNeill and N. C. Greenham, ACS Nano, 2014, 8, 3213.

46 J. Wang, K. Lin, K. Zhang, X. F. Jiang, K. Mahmood, L. Ying, F. Huang and Y. Cao, Adv. Energy Mater., 2016, 6, 1502563.

47 C. Goh, R. J. Kline, M. D. McGehee, E. N. Kadnikova and J. M. J. Fréchet, Appl. Phys. Lett., 2005, 86, 122110.

48 H. Q. Zhou, Y. Zhang, J. Seifter, S. D. Collins, C. Luo, G. C. Bazan, T.-Q. Nguyen and A. J. Heeger, Adv. Mater., 2013, 25, 1646.

49 P. P. Boix, M. M. Wienk, R. A. J. Janssen and G. GarciaBelmonte, J. Phys. Chem. C, 2011, 115, 15075.

50 C. D. Wanger, W. M. Riggs, L. E. Davis, J. F. Moulder and G. E. Muilenberg, Handbook of X-ray Photoelectron Spectroscopy, Perkin-Elmer Corp., Physical Electronics Division, Eden Prairie, Minnesota, USA, 1979.

51 L. Lee, J. X. Wang, R. R. Adzic, I. K. Robinson and A. A. Gewirth, J. Am. Chem. Soc., 2001, 123, 8838.

52 F. H. Li, A. Werner, M. Pfeiffer, K. Leo and X. Liu, J. Phys. Chem. B, 2004, 108, 17076.

53 F. H. Li, M. Pfeiffer, A. Werner, K. Harada, K. Leo, N. Hayashi, K. Seki, X. Liu and D. Dung, J. Appl. Phys., 2006, 100, 023716.

54 A. Werner, F. H. Li, K. Harada, M. Pfeiffer, T. Fritz, K. Leo and S. Machill, Adv. Funct. Mater., 2004, 14, 255.

55 A. Werner, F. Li, K. Harada, M. Pfeiffer, T. Fritz and K. Leo, Appl. Phys. Lett., 2003, 82, 4495. 